\title{
Reflexões sobre as atuações do bibliotecário e jornalista como agentes facilitadores na construção de saberes no combate à desinformação
}

\author{
Reflections on the actions of the librarian and journalist as \\ facilitating agents in the construction of knowledge in the fight \\ against disinformation
}

\author{
Laura Vilela Rodrigues Rezende a, c,* (iD) \\ Sonia Aguiar Cruz Riascos b (D)
}

Geisa Müller de Campos Ribeiro c (D)

\begin{abstract}
RESUMO: O presente trabalho inicialmente destaca a importância dos estudos sobre o fenômeno da informação no ambiente digital tecendo considerações sobre possibilidade de atuação interdisciplinar dos profissionais do campo da Ciência da Informação e da Comunicação, especificamente Bibliotecários e Jornalistas. A reflexão crítica, sobre possibilidades de trabalho conjunto destes profissionais no combate à infodemia e desinformação, traz como definição estrutural as práticas da cultura digital do autor Dalton Martins, caracterizadas como: informacionais, comunicacionais, relacionais e curatoriais. Dentro deste escopo, apresentam-se as aproximações na atuação de bibliotecários e jornalistas com base em suas competências e habilidades específicas. De forma geral, conclui-se que, embora hajam diferenças de temporalidade da atuação entre as duas áreas, uma vez que jornalistas lidam basicamente com informações que precisam ser reveladas de imediato, uma trajetória interdisciplinar que envolva o bibliotecário, neste contexto jornalístico, parece descortinar-se como um enorme potencial na alavancagem de ações de checagem de fatos (fact checking) ao possibilitar com precisão e confiabilidade uma retaguarda de fontes informacionais para as etapas iniciais do trabalho dos jornalistas, conferindo maior agilidade na produção de notícias.
\end{abstract}

Palavras-chave: Práticas da cultura digital; Bibliotecários; Jornalistas; Infodemia; Desinformação.

ABSTRACT: The present work initially highlights the importance of studies on the phenomenon of information in the digital environment. It makes considerations about the possibility of interdisciplinary action by professionals in the field of Information and Communication Science, specifically Librarians and Journalists. The critical reflection on the possibilities of these professionals' joint work in the fight against infodemic and misinformation brings as a structural definition the practices of digital culture proposed by the author Dalton Martins, characterized as: informational, communicational, relational and curatorial practices. Within this scope, approximations in the performance of librarians and journalists are presented and based on their specific skills and abilities. It was concluded that, although there are differences in the temporality of performance between both areas, since journalists basically deal with information that needs to be revealed immediately, an interdisciplinary trajectory that involves the librarian in this journalistic context appears to be unfolding as a huge potential for leveraging fact checking actions by making it possible to accurately and reliably back up information sources for the initial stages of the journalists' work, providing greater agility in the production of news.

Keywords: Digital cultural practices; Librarians; Journalists; Infodemic; Misinformation.

a Programa de Pós-Graduação em Comunicação e Informação, Universidade Federal de Goiás, Goiânia, GO, Brasil.

b Curso de Biblioteconomia e Gestão da Informação, Universidade Federal de Pernambuco, Recife, PE, Brasil.

‘Curso de Biblioteconomia, Universidade Federal de Goiás, Goiânia, GO, Brasil.

*Correspondência para/Correspondence to: Laura V. R. Rezende. E-mail: laura_rezende@ufg.br.

Recebido em/Received: 13/04/2021; Aprovado em/Approved: 31/05/2021.

Artigo publicado em acesso aberto sob licença CC BY 4.0 Internacional ()() 


\section{INTRODUÇÃO}

A época atual, intitulada por vários estudiosos como era da pós-modernidade, apresenta-se caracterizada por um novo olhar associativo entre razão e emoção, considerando as transformações sociais e culturais atreladas às tecnologias, pelo ineditismo da intensa diversidade, instabilidade e imprevisibilidade, realçando o papel da comunicação em outra ordem simbólica, segundo as ideias do sociólogo francês Michel Maffesoli (2019). Conceitos surgem para caracterizar as práticas culturais e seus desdobramentos, especialmente a cultura digital, que como afirma Santaella (2003), a disponibilidade, fluidez, capilaridade do desenho das redes e convergência das mídias favorecem a exacerbação da produção e circulação da informação.

A Pós-modernidade também inaugura uma reflexão prática e política sobre o que se deve entender por verdade e sua suposta autoridade. Dunker (2017) caracteriza a pósverdade como sendo uma verdade inflacionada de subjetividade, porém sem nenhum sujeito e que se confunde com processos sociológicos de individualização. Trata-se de circunstâncias em que apelos à emoção e crenças pessoais sobrepõem os fatos objetivos no tocante à opinião pública. As crenças impregnam todos os ramos, desde a política, a religião até a ciência trazendo uma verdade relativa, contextual, com distorções e ruídos capaz de moldar uma trajetória individual dentro de coletivos específicos, gerando as chamadas "bolhas digitais".

Pariser (2011) apresenta o conceito central dos filtros bolhas na personalização dos fluxos de informação. Essa tendência isola o usuário em comunidades que pensam e compartilham os mesmos valores e gera consequências sociais que surgem quando uma massa de pessoas começa a viver uma existência filtrada. Um fechamento que interfere na criatividade, inovação e geração de novas ideias, e que colocam o usuário mal informado a serviço da manipulação.

Parece correto considerar que as complexidades e os conflitos da humanidade se amplificam por meio do uso maciço das mídias digitais trazendo questões que carecem de reflexões e soluções, dentre elas a desordem informacional, tema que trataremos mais adiante.

Atualmente, a quantidade de pessoas que acessam a internet é cada vez maior. Segundo pesquisa anual realizada pelo Comitê Gestor de Internet (CGI), a TIC Domicílios de 2019, o Brasil possui 134 milhões de usuários da internet, o que representa cerca de $74 \%$ da população. O aparelho celular é o principal meio de acesso, com $99 \%$ do total (2019, p.8). Este cenário de utilização maciça do ambiente digital conectado se apresenta repleto de desafios, dentre eles a capacidade de saber selecionar e utilizar conteúdo de qualidade, conceito aqui utilizado para caracterizar a informação como sendo verdadeira e condizente com os fatos reais. Um estudo denominado "iceberg digital" divulgado em fevereiro de 2020, realizado na América Latina pela empresa de 
cibersegurança Kaspersky ${ }^{1}$, revelou que $62 \%$ dos brasileiros não sabem reconhecer se uma informação veiculada na Internet é falsa ou verdadeira. Tais dados quantitativos convidam a uma reflexão emergente sobre os caminhos possíveis de formação e construção de saberes visando amenizar ou superar os desafios provocados pela dinâmica da cultura digital (Kaspersky, 2020).

O campo da Ciência da Informação permite ressaltar, neste contexto, a importância da informação e seus elementos constitutivos, dentre eles os critérios de qualificação das fontes de informação como por exemplo: confiabilidade, autoridade, veracidade, cobertura, integridade e outros. Vergueiro (2010) diz que deve ser contemplada a definição de critérios que garantam ao usuário a fidedignidade, atualidade e confiança da informação disponibilizada pelos meios eletrônicos.

A qualidade informacional deve ser uma preocupação frequente dos profissionais que atuam com esse insumo intangível, indicando orientações para a identificação de critérios que possibilitem a avaliação das fontes diante do imenso fluxo informacional, segundo Tomaél (2008). Tais indicações podem apoiar os profissionais da informação na realização de seu trabalho para fornecer recursos informacionais qualificados aos clientes ou à comunidade.

A autora aponta os seguintes critérios para preliminar avaliação de fontes presentes na internet presentes nos indicadores: aspectos contextuais; aspectos de compartilhamento; aspectos intrínsecos; arquitetura da informação; credibilidade e representação. Consideram-se os critérios: adequação da fonte, links, facilidade de utilização; layout da fonte; informação de identificação; confiabilidade da informação; consistência da informação; restrições percebidas; suporte ao usuário (TOMAÉL et al., 2004; TOMAÉL, 2008).

Naumann e Rolker (2000) apontam como importantes as seguintes classificações: com orientação semântica baseada no significado de cada critério, orientada para o processamento, contemplando as fases do processo da informação e classificação orientada para objetivos baseados na finalidade da página da web. Outros critérios também abarcados para classificar a qualidade da informação: a percepção do usuário, a informação com valor em si mesma e a acessibilidade da informação. Os autores incluem características de qualidade como acurácia, completeza e Valor agregado.

Este artigo busca discutir a importância de estudos atuais sobre o fenômeno da informação no âmbito digital e as práticas da cultura digital, tecendo considerações sobre a atuação dos profissionais Bibliotecário e Jornalista, dos campos respectivos da Ciência da Informação e da Comunicação, de maneira interdisciplinar dando início a uma reflexão crítica sobre possibilidades de trabalho conjunto no combate à infodemia e à desinformação. As abordagens da Ciência da Informação reafirmam papel de destaque no tocante ao processo formativo de indivíduos como agentes críticos e

\footnotetext{
${ }^{1}$ Trata-se de uma empresa russa produtora e distribuidora de softwares de segurança para a Internet contra vírus, hackers, spam, trojans e spywares. Disponível em:

https://www.kaspersky.com.br/
} 
transformadores de sua realidade. Necessário se faz apresentar conceitos essenciais na direção da superação dos desafios postos.

\section{MANIFESTAÇÕES CONCEITUAIS SOBRE A DESORDEM INFORMACIONAL E SEUS DESDOBRAMENTOS}

$\mathrm{Na}$ atualidade, com a emergência da pandemia do novo agente do coronavírus (Covid19), tem sido posto um debate social sobre a desordem informacional e a infodemia, destacando a proliferação de informações falsas nos meios de comunicação e nas redes sociais, principalmente devido aos impactos destrutivos no âmbito político, econômico e social englobando aspectos relativos ao indivíduo e ao coletivo, ao escopo local e global.

Segundo a Organização Pan-Americana da Saúde (OPAS, 2020), que é uma divisão da Organização Mundial da Saúde (OMS), infodemia se refere ao fenômeno de excesso de informações, precisas ou não, que tornam difícil a localização de fontes idôneas e orientações confiáveis, e podem se alastrar rapidamente como um vírus, principalmente pelo consumo de redes sociais.

Esse contexto digital desordenado de democratização do uso e consumo das mídias, provoca uma metamorfose no que se costumava chamar de espaço público e formação de opinião, inaugurando uma vitrine consumível de informações falsas, distorcidas e manipuladas, talvez o desafio mais notório desta Era atual.

Para Leite e Matos (2017, p. 2346):

Se algum dia a informação já foi escassa, hoje ela é excedente. Este excesso parece sobrecarregar o sistema cognitivo e fazer com que a informação perca sua principal função: informar.

É neste sentido que a informação se torna apenas produto de marketing, status ou instrumento de manipulação social e distancia-se da sua principal finalidade que é o uso contextualizado para a construção do conhecimento.

No rol desses desafios, a desinformação se configura como um dos fenômenos negativos e apresenta conjuntos de significados. Um deles é proposto pelo Manual de Educação e Capacitação em Jornalismo, recém publicado pela UNESCO em 2020. Os autores Claire Wardle e Hossein Derakhshan falam sobre a desordem da informação (2020, p.44-45; 2017, p.20):

Grande parte do discurso sobre fake news ou "notícias falsas" combina duas noções: informação falsa [misinformation, em inglês] e desinformação [disinformation]. No entanto, os autores propõem que no contexto da informação falsa, quem está divulgando acredita que seja verdade. Sobre a desinformação pode-se afirmar que também se trata de uma informação falsa, sendo que quem 
espalha, sabe que é falso. É uma mentira deliberada e intencional que sinaliza que as pessoas estão sendo ativamente mal informadas por agentes mal intencionados. Uma terceira categoria pode ser chamada de informação maliciosa [mal information, em inglês] que são as informações baseadas na realidade, porém usadas para prejudicar uma pessoa, organização ou país. É importante distinguir as mensagens verdadeiras daquelas que são falsas, mas também daquelas que são verdadeiras (e aquelas mensagens com alguma verdade), mas que são criadas, produzidas ou distribuídas por "Agentes" com a intenção de prejudicar, em vez de servir ao interesse público.

Apesar das distinções acima, as consequências maléficas podem ser semelhantes, corrompendo a integridade do processo democrático ou até mesmo direcionando a procedimentos incorretos relacionados à saúde da população. Além disso, em alguns casos pode haver a combinações dessas três conceituações, sendo didático e útil manter as distinções em mente uma vez que as causas, técnicas e recursos podem variar. A figura a seguir exemplifica e estabelece distinções sobre os conceitos apresentados.

Figura 2. Desordem da Informação.

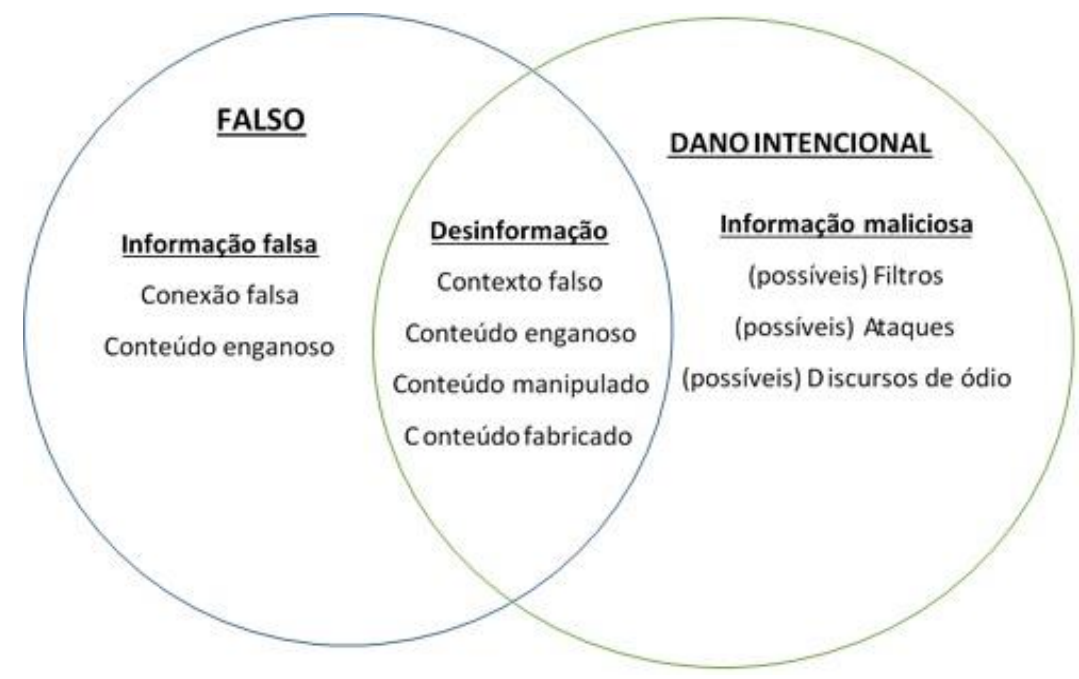

Fonte: Adaptado de UNESCO (2020, p.45)

Diante do exposto, surge a necessidade cada vez mais latente de se pensar em desenhos de atuação interdisciplinar no combate à desinformação. Faz-se necessário, inicialmente, trazer para esta reflexão algumas características acerca da atuação dos profissionais da Comunicação Social, em especial da área de Jornalismo, e do labor dos Bibliotecários, representando a área da Ciência da Informação. 


\section{ATUAÇÕES PROFISSIONAIS ESSENCIAIS NAS PRÁTICAS DAS CULTURAIS DIGITAIS}

Conforme Borko (1968, p. 3), a "Ciência da Informação é a ciência que investiga propriedades e comportamento da informação, as forças que governam o fluxo de informação e os meios de processar informação para otimizar o acesso e uso". Definição ainda vigente que se insere no escopo das pesquisas da Ciência da Informação (Cl), ou seja, "[...] o corpo de conhecimento relacionado com origem, coleção, organização, armazenamento, recuperação, interpretação, transmissão, transformação, e utilização da informação" (Borko, 1968, p. 3).

Importante ressaltar a natureza interdisciplinar da $\mathrm{Cl}$ e as relações intrínsecas com a Biblioteconomia, a Comunicação e a Ciência da Computação, segundo os estudos de Saracevic (1999). Pinheiro (1999) discorre, também, sobre essa interdisciplinaridade, sugerindo uma fusão da $\mathrm{Cl}$ com a Comunicação, denominando-a "Infocomunicação".

A área do Jornalismo vem sendo diretamente afetada em virtude da sua função social primeira de veicular informação verídica de interesse público, enfrentando, então, a urgência de combater os impactos nocivos da má comunicação. Concomitantemente, no entanto menos tratado pelos órgãos internacionais, está o campo da Ciência da Informação que tem como área de estudos o fenômeno da informação.

Tanto o Jornalismo quanto a Ciência da Informação se deparam com a crítica missão de trazer novos conceitos e paradigmas diante das mudanças no ambiente midiático e informacional, respectivamente. No âmbito do Jornalismo, surgiu a new literacy ou alfabetização jornalística, e na sequência, vem sendo configurados os construtos da alfabetização midiática. Desde o final dos anos 1980, a Ciência da Informação vem tratando, com maior ênfase, o tema da alfabetização informacional, aportando avanços teóricos com aplicabilidade, ao longo das décadas subsequentes, para o desenvolvimento de competências no contexto das práticas da cultura digital.

Caracterizando dinamicamente a cultura digital, Martins (2018, p.5-9) a define como um conjunto de práticas sociais que acontecem de forma singular, ou seja, exclusivamente no espaço sócio digital. $\mathrm{O}$ autor ainda caracteriza tais práticas do ponto de vista da manipulação simbólica, ou seja, da manipulação da linguagem, em quatro conjuntos:

- Práticas informacionais: Caracterizadas por um conjunto de práticas sociais relacionadas às práticas de moldar, dar forma à matéria do digital, mixar e remixar os elementos simbólicos à luz de sua capacidade automática de processamento;

- Práticas comunicacionais: Podem ser percebidas pelas estratégias de fazer circular os conteúdos digitais, pôr em movimento e se fazer chegar de um ponto a outro de uma rede de nós em conexão. Surgem novas dinâmicas de conversação, novos tipos de mensagens produzidas, novos coletivos temáticos de pessoas para socialização; 
- Práticas relacionais: Caracterizadas pelo surgimento das inúmeras experiências de formação de grupos, coletivos e, sobretudo, das mídias sociais. Novas formas de relacionamento entre indivíduos e entre estes e recursos materiais, proporcionando mudanças em experiências cotidianas de consumo e interação relacionadas com transporte, turismo, moradia, alimentação;

- Práticas curatoriais: Caracterizadas pelos filtros de significância e relevância estabelecidos por meio de funcionalidades específicas nos aplicativos de mídias sociais. Do ponto de vista dos indivíduos, estas práticas ocorrem intencionalmente ou não, sendo responsáveis pela interação e calibragem dos algoritmos desses aplicativos, possibilitando descobertas de preferências e interesses selecionando e disponibilizando apenas parte da totalidade dos conteúdos disponíveis para visualização.

Tomando como arcabouço teórico para as reflexões a caracterização das práticas sociais na cultura digital de Martins (2018), destaca-se a importância tanto do papel dos Cientistas da Informação, dedicados aos estudos do fenômeno da informação, englobando a qualidade da informação, reforçando a relevância do papel dos Bibliotecários como agentes mediadores, quanto do papel dos Comunicadores, em específico dos Jornalistas, atuantes no processo da comunicação da notícia real, fornecendo informações e comentários verificáveis voltados ao interesse público, demonstrando, ainda, o importante valor da mídia.

Esse cenário evidencia a necessidade de competência crítica para avaliar a credibilidade da informação e sua identificação ética, que é vital para o fortalecimento da cidadania (BRISOLA, SCHNEIDER, SILVA JUNIOR, 2017). A perspectiva ética deste contexto é fundamental pois está relacionada a experiência cotidiana dos indivíduos e a interculturalidade em informação existente, resultante também das práticas da cultura digital apresentadas por Martins (2018).

\section{Formação profissional do Bibliotecário}

Apresenta-se a formação, no Brasil, ao nível de graduação dos Cursos de Jornalismo e Biblioteconomia, objetivando categorizar as diferentes atuações dos respectivos profissionais dessas áreas no contexto da construção de saberes no combate à desinformação. Além disso, movimentações de aproximação entre as duas áreas feitas por algumas entidades coletivas.

Em relação à formação do profissional Bibliotecário, de acordo com o Parecer do CNE/CES n492/2001 de 03/04/2001, documento do Conselho Nacional de Educação da Câmara Superior de Educação do Ministério da Educação (2001, p.32-33), que estabelece as diretrizes curriculares nacionais dos cursos de Biblioteconomia, dentre as competências e habilidades específicas típicas previstas, destacam-se:

Interagir e agregar valor nos processos de geração, transferência e uso da informação, em todo e qualquer ambiente; 
Criticar, investigar, propor, planejar, executar e avaliar recursos e produtos de informação;

Trabalhar com fontes de informação de qualquer natureza;

Processar a informação registrada em diferentes tipos de suporte, mediante a aplicação de conhecimentos teóricos e práticos de coleta, processamento, armazenamento e difusão da informação; Realizar pesquisas relativas a produtos, processamento, transferência e uso da informação.

O Código Brasileiro de Ocupações (2021, s.p.), desenvolvido pelo extinto Ministério do Trabalho, traz as seguintes funções do profissional Bibliotecário:

\begin{abstract}
Disponibilizam informação em qualquer suporte; gerenciam unidades como bibliotecas, centros de documentação, centros de informação e correlatos, além de redes e sistemas de informação. Tratam tecnicamente e desenvolvem recursos informacionais; disseminam informação com o objetivo de facilitar o acesso e geração do conhecimento; desenvolvem estudos e pesquisas; realizam difusão cultural; desenvolvem ações educativas. Podem prestar serviços de assessoria e consultoria.
\end{abstract}

Considerando a importância de atuação com as funções supramencionadas, Saracevic (2014, p.1), embora reconheça que os esforços de alfabetização informacional são globais, em seu artigo intitulado Information Literacy in the United States: Contemporary Transformations and Controversies indica a linha do tempo dos esforços de alfabetização informacional empreendidos pela Biblioteconomia:

\begin{abstract}
A American Library Association (ALA) publicou no ano 2000 um conjunto de padrões que fornecia uma estrutura para avaliar o indivíduo alfabetizado em informação. Em 2013, percebeu-se que muitas mudanças exigem uma atualização e até mesmo novas abordagens para a alfabetização informacional. No início de 2014, a ALA propôs um esboço inicial de uma nova estrutura para a alfabetização informacional para o ensino superior. Uma nova definição de alfabetização informacional foi oferecida, juntamente com uma nova estrutura baseada em conceitos de limiar - revisada criticamente no artigo. Durante o ano de 2014 foram realizados diversos debates públicos para a estrutura.
\end{abstract}

Esta mesma entidade coletiva, a American Library Association (ALA) elaborou a publicação Guidelines for the Introduction of Electronic Information Resources to Users, ou Diretrizes para a Introdução de Recursos de Informação Eletrônica aos Usuários, que foi preparada pelo Comitê de Gestão da Seção de Referência Assistida por Máquina (MARS), Associação de Serviços de Referência e Usuário (RUSA), American Library Association. Foi aprovada pelo Conselho de Administração da RUSA, junho de 1997; revisada pelo Comitê de Gestão de Recursos Eletrônicos e Serviços do MARS, janeiro de 2006; tendo sido aprovada tal revisão pelo Conselho de Administração da RUSA, junho de 2006. Segue-se o trecho dedicado à Educação/instrução do usuário (Rusa, 2006, s.p.) para Unidades de Informação: 
Determine o tipo e nível apropriado de instrução para um novo recurso de informação eletrônica.

Determine até que ponto o serviço deve ser incorporado às instruções do usuário existentes e até que ponto as novas sessões ou métodos de ensino seriam úteis.

Projetar instruções do usuário para acomodar vários estilos de aprendizagem e níveis de experiência e incluir uma combinação de instruções de ponto de uso para indivíduos, instrução em grupo, assistência de colegas (tanto usuário-usuário quanto instrutorinstrutor), tutoriais, documentação e / ou sinalização.

É importante salientar que, em complementação as definições da ALA, não consideramos a competência em informação como uma prática que converte o aprendizado à aquisição da competência baseada no 'saber proceder' como algo muito operacional. Mas de um processo reflexivo e ético. É preciso pensar a competência informacional a partir de superação dos obstáculos semânticos que instrumentalizam seus preceitos (BEZERRA; SCHNEIDER, SALDANHA, 2019). A competência crítica informacional requer, segundo Brisola, Schneider e Silva Junior (2017), uma problematização conceitual, psicológica e pragmática das necessidades informacionais

\section{Formação profissional do Jornalista}

No contexto do processo formativo do profissional da área de comunicação, de acordo com o Parecer CNE/CES n492/2001 de 03/04/2001 (Ministério da Educação, 2001, p.17) que estabelece as diretrizes curriculares nacionais dos cursos de Comunicação Social e suas respectivas habilitações, ressaltam-se algumas competências e habilidades específicas previstas nestes cursos de graduação no Brasil, considerando a habilitação de Jornalismo:

Produção de informações relacionadas a fatos, circunstâncias e contextos do momento presente;

Exercício da objetividade na apuração, interpretação, registro e divulgação dos fatos sociais;

Exercício da tradução e disseminação de informações de modo a qualificar o senso comum;

Exercício de relações com outras áreas sociais, culturais e econômicas com as quais o jornalismo faz interface.

Quanto às funções dos Jornalistas, o Código Brasileiro de Ocupações (2021, s.p.) dispõe que estes profissionais:

Recolhem, redigem, registram através de imagens e de sons, interpretam e organizam informações e notícias a serem difundidas, expondo, analisando e comentando os acontecimentos. Fazem seleção, revisão e preparo definitivo de textos a serem divulgados em jornais, revistas, televisão, rádio, internet, assessorias de imprensa e quaisquer outros meios de comunicação com o público. 
Recentemente, a UNESCO lançou a publicação “Iniciativa Global pela Excelência no Ensino de Jornalismo", para apoiar o seu Programa Internacional para o Desenvolvimento de Comunicação (PIDC). Essa iniciativa foi desenvolvida com o propósito de servir como um modelo internacional de currículo adaptável para responder ao problema emergente da desinformação global (Unesco, 2020, p.6).

De antemão, a UNESCO (2020, p.6) alerta nesta publicação acerca do uso errôneo para o termo fake news ou notícias falsas, tendo em vista que "notícias" significam informações verificáveis de interesse público; logo a denominação "notícia falsa" passa a ideia de "minar" a credibilidade de uma informação que atende ao critério de veracidade e atende ao interesse público, ou seja, trata-se de notícia real. A UNESCO indica, ainda, que ocorre a manipulação exploratória da linguagem e das convenções dos gêneros de notícias.

O movimento de combate à desinformação no escopo jornalístico fez surgir um novo campo de atuação que se espalhou pelo mundo ganhando protagonismo desde 2016, quando das eleições dos Estados Unidos da América, Brexit ${ }^{2}$. Trata-se da checagem profissional de fatos (fact-checking). Este tipo de atuação em geral é realizado por jornalistas individuais, vinculados a agências específicas de checagem de fatos ou atuando em um setor específico de algum veículo de comunicação previamente consolidado. Um dos marcos essenciais para esta atuação profissional foi a criação em 2015 da Rede Internacional de Checagem de Fatos, a IFCN (International Fact-Checking Network ${ }^{3}$ ). Essa rede tem como funções (IFCN, 2021):

- Monitorar tendências, formatos e formulação de políticas sobre checagem de fatos em todo o mundo;

- Ajuda a divulgar possíveis diretrizes comuns entre os checadores de fatos do mundo;

- Promove padrões básicos por meio do código de princípios e projetos;

- Financiar e apoiar Iniciativas (inovadoras) de checagem de fatos;

- Reunir checadores de fatos em conferências visando promover esforços colaborativos na área;

Oferece treinamentos.

A IFCN (2021, Tradução nossa, s.p.) possui um processo de avaliação da conduta desempenhada pelas agências/sites de checagem de fatos dentro de parâmetros previamente estabelecidos alinhados ao código de princípios da rede. Estes princípios são pautados na transparência em relação ao apartidarismo, fontes de informação utilizadas, financiamento e estrutura organizacional, metodologia de checagem e política de retratação/correção. No momento desta pesquisa, a rede indicou que possui cerca de cem (100) agências ou sites checadores que fazem parte da rede, foram avaliados e que possuem o selo de avaliação.

\footnotetext{
${ }^{2}$ Termo criado na língua inglesa para caracterizar a saída do Reino Unido (UK) da União Europeia. O termo significa a junção das palavras British (britânico) e exit (saída).

3 Disponível em: https://www.poynter.org/ifcn/
} 
O laboratório americano Duke Reporter's Lab localizado em Durham, na Carolina do Norte realiza anualmente um censo mundial de agências/sites checadores de fatos. Em 2020, o último levantamento 4 identificou 290 agências/sites checadores em 83 países. Este número sinaliza para um crescimento relevante em comparação ao ano de 2014, quando da primeira edição deste censo, que identificou somente 44 agências. Destacase no contexto jornalístico o incansável papel das agências/sites/ profissionais checadores de fatos que tentam prestar um serviço de caráter informativo em favor da proliferação de informação de qualidade.

\section{Interdisciplinaridade entre a atuação do Bibliotecário e do Jornalista no combate à desinformação}

No âmbito do Jornalismo, a ALA começou em 2006, a partir do Comitê de Estudos de Comunicação da ACRL (Association of College \& Research Libraries, Education \& Behavioral Sciences Section), com uma série de ações colaborativas envolvendo entidades coletivas objetivando desenvolver padrões de competência em alfabetização informacional para estudantes de graduação em Jornalismo, estudantes de pós-graduação e profissionais. Os membros do Comitê realizaram uma revisão da literatura, consultaram organizações profissionais de Jornalismo de 2007-2009, reuniram-se com professores de Comunicação e Jornalismo em 2007, apresentaram uma proposta na Conferência da National Communication Association de 2007, participaram de discussões da ACRL relacionadas aos padrões de competência em alfabetização informacional nas disciplinas, e se reuniu com um consultor de Literacia em Informação da ACRL em 2008. O Comitê visou fornecer à época, para a comunidade acadêmica e ao profissional do Jornalismo um conjunto útil de competências e exemplos de pesquisas bem sucedidas na disciplina (Association, 2011, p.1).

A seguir os padrões de competência em alfabetização informacional para estudantes de graduação em Jornalismo (Association, 2011, Tradução nossa, p. 3-13):

O $1^{\circ}$ padrão trata do Planejamento prevendo identificar os recursos necessários, determinar onde encontrá-los e estimar o tempo e os custos financeiros para acessar as informações. Inclui os indicadores: 1.1 Definir a necessidade de informação com base na ideia da história ou pergunta de pesquisa; 1.2. Identificar uma variedade de fontes de informação para atender às necessidades de informação; 1.3. Considerar os custos financeiros e o tempo necessário para obter informações.

O $2^{\circ}$ padrão trata da Busca, ou seja, o início da investigação usando estratégias de pesquisa eficazes e eficientes. Inclui os indicadores: 2.1 Construir e implementar estratégias de pesquisa efetivamente projetadas; 2.2. Recuperar informações online ou pessoalmente usando uma variedade de métodos; 2.3. Refinar métodos

\footnotetext{
${ }^{4}$ Disponível em: https://reporterslab.org/annual-census-finds-nearly-30o-fact-checkingprojects-around-the-world/
} 
investigativos e estratégias de pesquisa; 2.4 Usar gerenciamento de registros e habilidades de citação de recursos.

O $3^{\circ}$ padrão aborda a avaliação para precisão, ou seja, avaliar as informações coletadas quanto à precisão, equilíbrio e relevância. Os indicadores são: 3.1 Resumir e sintetizar as principais ideias das informações coletadas; 3.2. Avaliar a credibilidade das informações coletadas; 3.3. Sintetizar as ideias principais para gerar novos conhecimentos ou ideias para histórias; 3.4 Comparar o novo conhecimento com o conhecimento prévio para determinar o valor agregado, as contradições ou outras características únicas da informação; 3.5 Validar o conhecimento e a interpretação das informações por meio do diálogo com outras pessoas; 3.6 Decidir se a pergunta inicial ou ideia da história deve ser revisada.

O $4^{\circ}$ padrão aborda a Redação e Criação, ou seja, a escrita da história integrando as informações coletadas. Os indicadores são: 4.1. Aplicar as informações coletadas ao planejamento e à criação de uma história ou produto de pesquisa; 4.2 Revisar o processo de desenvolvimento para a história ou produto de pesquisa; 4.3 Apresentar efetivamente a história ou projeto de pesquisa para o público-alvo.

O $5^{\circ}$ e último padrão trata de questões éticas e legais aplicando padrões profissionais em todo o processo de pesquisa. Os indicadores são: 5.1 Reconhecer as questões éticas, legais e socioeconômicas em torno da informação e da tecnologia; 5.2. Seguir leis, regulamentos, políticas institucionais para o uso ético de informações; 5.3 Citar o trabalho de outros e pedir permissão quando necessário.

A seguir, decidiu-se por construir um quadro apresentando as práticas da cultura digital propostas por Martins (2018) relacionando-as com possíveis atuações dos profissionais Bibliotecários e Jornalistas. O conteúdo do quadro foi estruturado baseando-se no contexto brasileiro, especificamente o processo formativo desses profissionais, em especial, no tocante às habilidades e competências específicas essenciais propostas pelo Parecer do CNE/CES n492/2001 de 03/04/2001 (Ministério da Educação, 2001), funções definidas pelo Código Brasileiro de Ocupações (CBO) e os padrões de competência em alfabetização informacional para estudantes de graduação em Jornalismo (ASSOCIATION, 2011, Tradução nossa, p. 3-13). Ressalta-se aqui que, embora existam outras fontes informacionais relevantes para se regular, definir e entender a atuação profissional no Brasil, em destaque os conselhos/entidades de classe de cada profissão, optou-se por realizar um recorte e analisar as fontes supracitadas. 
Quadro 1. Orientações para a atuação de Bibliotecários e Jornalistas nas práticas da cultura digital.

\begin{tabular}{|c|c|c|}
\hline Práticas da cultura digital & Atuação do bibliotecário & Atuação do profissional Jornalista \\
\hline Práticas informacionais & $\begin{array}{l}\text { - Aplicar padrões profissionais éticos em todos } \\
\text { - Interagir e agregar valor nos processos de } \\
\text { geração, transferência e uso da informação, } \\
\text { em todo e qualquer ambiente; } \\
\text { - Determinar o tipo e nível apropriado de } \\
\text { orientação a ser dado ao usuário final sobre } \\
\text { um novo conteúdo digital; } \\
\text { - Trabalhar com fontes de informação de } \\
\text { qualquer natureza aplicando critérios de } \\
\text { determinação da qualidade; } \\
\text { - Criticar, investigar, propor, planejar, } \\
\text { executar e avaliar recursos e produtos de } \\
\text { informação. }\end{array}$ & $\begin{array}{l}\text { - Aplicar padrões profissionais éticos em todos os } \\
\text { processos; } \\
\text { - Identificar os recursos informacionais } \\
\text { necessários, determinar onde encontrá-los e } \\
\text { estimar o tempo e os custos financeiros para } \\
\text { acessar as informações; } \\
\text { - Construir e implementar estratégias de pesquisa } \\
\text { efetivamente projetadas (pesquisa, } \\
\text { recuperação, refinamento e citação); } \\
\text { - Avalia as informações coletadas quanto à } \\
\text { precisão, confiabilidade, equilíbrio e relevância. } \\
\text { - Produzir informações relacionadas a fatos, } \\
\text { circunstâncias e contextos do momento } \\
\text { presente. }\end{array}$ \\
\hline Práticas comunicacionais & $\begin{array}{l}\text { - Aplicar padrões profissionais éticos em todos } \\
\text { os processos; } \\
\text { - Criticar, investigar, propor, planejar, } \\
\text { executar e avaliar recursos e produtos de } \\
\text { informação; } \\
\text { - Processar a informação registrada em } \\
\text { diferentes tipos de suporte, mediante a } \\
\text { aplicação de conhecimentos teóricos e } \\
\text { práticos de coleta, processamento, } \\
\text { armazenamento e difusão da informação. }\end{array}$ & $\begin{array}{l}\text { - Aplicar padrões profissionais éticos em todos os } \\
\text { processos; } \\
\text { - Exercer a objetividade na apuração, } \\
\text { interpretação, registro e divulgação dos fatos } \\
\text { sociais; } \\
\text { - Realizar a tradução e disseminação de } \\
\text { informações de modo a qualificar o senso } \\
\text { comum. }\end{array}$ \\
\hline
\end{tabular}




\begin{tabular}{|c|c|c|}
\hline Práticas relacionais & $\begin{array}{l}\text { - Aplicar padrões profissionais éticos em todos } \\
\text { os processos; } \\
\text { - Criticar, investigar, propor, planejar, } \\
\text { executar e avaliar recursos e produtos de } \\
\text { informação; } \\
\text { - Realizar pesquisas relativas a produtos, } \\
\text { processamento, transferência e uso da } \\
\text { informação; } \\
\text { - Propor adaptações e novas orientações aos } \\
\text { usuários (existentes) para utilização de } \\
\text { novos conteúdos digitais. }\end{array}$ & $\begin{array}{l}\text { - Aplica padrões profissionais éticos em todos os } \\
\text { processos; } \\
\text { - Estabelecer relações com outras áreas sociais, } \\
\text { culturais e econômicas com as quais o } \\
\text { jornalismo faz interface; } \\
\text { - Realizar tradução e disseminação de } \\
\text { informações de modo a qualificar o senso } \\
\text { comum. }\end{array}$ \\
\hline Práticas curatoriais & $\begin{array}{l}\text { - Aplica padrões profissionais éticos em todos } \\
\text { os processos; } \\
\text { - Criticar, investigar, propor, planejar, } \\
\text { executar e avaliar recursos e produtos de } \\
\text { informação; } \\
\text { - Processar a informação registrada em } \\
\text { diferentes tipos de suporte, mediante a } \\
\text { aplicação de conhecimentos teóricos e } \\
\text { práticos de coleta, processamento, } \\
\text { armazenamento e difusão da informação; } \\
\text { - Propor adaptações e novas orientações aos } \\
\text { usuários (existentes) para utilização de } \\
\text { novos conteúdos digitais. } \\
\text { - Realizar pesquisas relativas a produtos, } \\
\text { processamento, transferência e uso da } \\
\text { informação visando orientar os usuários } \\
\text { finais quanto aos filtros de significância. }\end{array}$ & $\begin{array}{l}\text { - Aplica padrões profissionais éticos em todos os } \\
\text { processos; } \\
\text { - Exercer a objetividade na apuração, } \\
\text { interpretação, registro e divulgação dos fatos } \\
\text { sociais; } \\
\text { - Estabelecer relações com outras áreas sociais, } \\
\text { culturais e econômicas com as quais o } \\
\text { jornalismo faz interface; } \\
\text { - Realizar tradução e disseminação de } \\
\text { informações de modo a qualificar o senso } \\
\text { comum. }\end{array}$ \\
\hline
\end{tabular}




\section{CONCLUSÕES}

Este trabalho destacou, inicialmente, a importância dos estudos sobre o fenômeno da informação no ambiente digital. Neste contexto, foram apresentados conceitos e um recorte do arcabouço teórico que a Ciência da Informação disponibiliza, especialmente em se tratando das propriedades, tratamento e processos da informação, objetivando otimizar seu acesso e uso. Objetivou apresentar relações possíveis entre as áreas da Comunicação e da Ciência da Informação, tendo como propósito essencial o combate à desinformação.

Para contextualizar e embasar a interdisciplinaridade de atuação, optou-se por apresentar o estudo de Martins (2018) que caracteriza as práticas da cultura digital em: informacionais, comunicacionais, relacionais e curatoriais.

No escopo das práticas digitais propostas pelo autor, considerando a expertise do profissional Bibliotecário que atua no processo formativo do pensamento crítico de cidadãos, sua contribuição soma-se para além da detecção de erros, imprecisões e mentiras com a atividade da verificação de fatos e(ou) a comprovação de dados em discursos e outras publicações veiculadas nos meios de comunicação e mídias digitais, empreendidas pelos jornalistas e demais atores que participam do combate à desinformação.

Ao relacionar a atuação dos dois profissionais no contexto das práticas culturais digitais com base nas habilidades específicas das profissões, dos Pareceres da CNE/CES do Ministério da Educação, bem como da Classificação Brasileira de Ocupações, somadas às recomendações de incremento para a formação do graduando em Jornalismo, propostas pela American Library Association, e a publicação Guidelines for the Introduction of Electronic Information Resources to Users para o profissional Bibliotecário, logrou-se constatar que essas fontes informacionais propiciaram maior reflexão para tecer interações estreitas entre as áreas do conhecimento aqui tratadas, e sobretudo, para o exercício profissional conjunto direcionado às práticas culturais digitais informacionais e comunicacionais.

As informacionais lidam com a (co) criação de conteúdo, incluindo suas mixagens e reconfigurações favorecidas pelo processamento automático. Sugere-se para Jornalistas e Bibliotecários maior atenção às estratégias de pesquisa e coleta das informações considerando, sobretudo, os critérios de precisão, confiabilidade, equilíbrio e relevância, dentre outros importantes para a garantia da qualificação informacional.

Sugere-se que tanto na atuação do Bibliotecário quanto na do Jornalista frente às práticas comunicacionais, sejam direcionados esforços maiores no tocante às questões com a crítica, a investigação, o planejamento e a avaliação de recursos informacionais, 
de modo a perseguir maior acurácia, viabilizando, inclusive, a divulgação via novas dinâmicas de conversação.

Quanto às práticas relacionais e curatoriais, estas trouxeram atuações voltadas para a interação com outras áreas do conhecimento. Para o labor do Bibliotecário tornou-se necessário considerar adaptações e orientações aos novos tipos de conteúdos digitais que propõem outras relações entre os novos coletivos e as mudanças em experiências cotidianas de consumo. Considerar as questões que envolvem os filtros de relevância e significância determinam, aos dois campos profissionais deste estudo, atuações que priorizam o cuidado durante as investigações iniciais das fontes informacionais. Nesse sentido, torna-se importante, no caso do Bibliotecário, conceber adaptações no seu trabalho de formação dos usuários finais para que estes possam desenvolver o pensamento crítico frente aos desafios informacionais na pós-modernidade, considerando a aplicabilidade destas práticas. Ao Jornalista, urge que empreenda estudos para lograr melhores formas de traduzir e adaptar o conteúdo gerado, em menor tempo, com maior segurança para que a disseminação se torne mais efetiva e eficaz.

As ações de combate à desinformação, de maneira geral, têm ocorrido no mundo todo, dando destaque à atuação de Jornalistas, sites e agências de checagem de fatos. Embora várias iniciativas estejam em curso, a rapidez com que as informações falsas e maliciosas têm ganhado força alimentando o cenário de desordem informacional é infinitamente superior. Entende-se que a checagem de fatos é uma atuação relevante, embora não efetue a transformação que deve ocorrer na sociedade. Sabe-se, no entanto, que outros ferramentais podem vir a auxiliar no combate aos problemas informacionais da atualidade. Os recursos tecnológicos isolados auxiliam, mas não modificam o status quo. Logo, depreende-se que a formação de indivíduos com pensamento crítico se torna vital para garantir a cidadania inteligente. Caminho este promissor no sentido de trazer frutos duradouros e mais concretos do que a fluidez da checagem de fatos.

Embora esteja claro que existe uma diferença de temporalidade na atuação do profissional Bibliotecário e na do Jornalista, visto que este último lida com informações que precisam ser reveladas de imediato, parece correto concluir que uma trajetória interdisciplinar envolvendo os profissionais destas áreas possui um enorme potencial em alavancar as ações de checagem de fatos em andamento. Entende-se que a participação de bibliotecários nas equipes de checagem de fatos pode proporcionar uma retaguarda na viabilização do trabalho com as fontes informacionais para as etapas iniciais do trabalho dos jornalistas, conferindo maior agilidade e confiabilidade na produção de notícias. 


\section{REFERÊNCIAS}

ASSOCIATION OF COLLEGE E RESEARCH LIBRARIES, 2011. Information Literacy Competency Standards for Journalism Students and Professionals [em linha]. Chicago: ALA. [Acesso em 26 março 2021]. Disponível em: http://www.ala.org/acrl/sites/ala.org.acrl/files/content/standards/il_journalism.pdf

Bezerra, A, C, Schneider, M, Saldanha, G, S. Competência crítica em informação como crítica à competência em informação. Informação e sociedade: Estudos, [em linha]. 2019. Vol 29, n. 3, p. 5-22. Disponível em: https://periodicos.ufpb.br/ojs/index.php/ies/article/view/47337

BRISOLA, A, C, SCHNEIDER, M, A, F, SILVA JÚNIOR, J, F. Competência crítica em informação, ética intercultural da informação e cidadania global na era digital: fundamentos e complementaridades. Encontro Nacional de Pesquisa em Ciência da Informação, n. XVIII ENANCIB, 2017. Disponível em: http://hdl.handle.net/20.500.11959/brapci/105022.

CBO. CLASSIFICAÇÃO BRASILEIRA DE OCUPAÇÕES, 2021. Profissionais da Informação, Bibliotecário [em linha]. [Acesso em 26 março 2021]. Disponível em: http://www.mtecbo.gov.br/cbosite/pages/pesquisas/ResultadoOcupacaoMovime ntacao.jsf

CBO. CLASSIFICAÇÃO BRASILEIRA DE OCUPAÇÕES, 2021. Profissionais do Jornalismo, Jornalista [em linha]. [Acesso em 26 março 2021]. Disponível em: http://www.mtecbo.gov.br/cbosite/pages/pesquisas/ResultadoOcupacaoMovime ntacao.jsf

CGI, 2019. TIC Domicílios. Coletiva de imprensa [em linha]. 26, mai 2020. [Acesso em 26 março 2021]. Disponível em:

https://cetic.br/media/analises/tic_domicilios_2019_coletiva_imprensa.pdf

DUNKER, Christian, TEZZA, Cristóvão, FUKS, Julián, TIBURI, Márcia, SAFATLE, Vladimir, 2017. Ética e pós- verdade. Porto Alegre: Ed.Dublinense.

INTERNATIONAL FACT-CHECKING NETWORK - IFCN, 2021. The International FactChecking Network [em linha]. [Acesso em 26 março 2021]. Disponível em: https://www.poynter.org/ifcn/

KASPERSKY, 2020. 62\% dos brasileiros não sabem reconhecer uma notícia falsa. Comunicado à imprensa [em linha]. 13, fev 2020. [Acesso em 14 março 2021]. Disponível em: https://www.kaspersky.com.br/about/press-releases/2020_62-dosbrasileiros-nao-sabem-reconhecer-uma-noticia-falsa .

LEITE, Leonardo Ripoll Tavares, MATOS, José Claudio, 2017. Zumbificação da informação: a desinformação e o caos informacional. Revista Brasileira de Biblioteconomia e Documentação [em linha]. 2017. vol. 13, p. 2334-2349. [Acesso em 28 março 2021]. Disponível em: https://rbbd.febab.org.br/rbbd/article/view/918

MAFFESOLI, Michel. Desencantamento e reencantamento: Michel Maffesoli fala sobre o pensamento pós-moderno na FAMECOS. [Entrevista cedida a PPGCOM, PUCRS, Porto Alegre, 2019. Disponível em: http://projetos.eusoufamecos.net/b- 
ppgcom/2019/05/30/desencantamento-e-reencantamento-michel-maffesoli-falasobre-o-pensamento-pos-moderno-na-famecos/

MARTINS, Dalton Lopes, 2018. As práticas da cultura digital. Revista do Centro de Pesquisa e Formação [em linha]. 2018. no. 7, p. 51-60. [Acesso em 02 fevereiro 2021]. Disponível em:

https://www.sescsp.org.br/files/artigo/bgf41213/29af/44b8/9c66/ae47437a7b3e.pdf

MINISTÉRIO DA EDUCAÇÃO, 2001. Parecer CNE/CES n4492/2001 de 03/04/2001 que estabelece as diretrizes curriculares nacional do curso de Biblioteconomia [em linha]. 03 abril 2001. [Acesso em 27 março 2021]. disponível em: http://portal.mec.gov.br/cne/arquivos/pdf/2001/pces492_01.pdf

NAUMANN, Felix; ROLKER, Claudia. Assessment methods for information quality criteria. German Research Society, Berlin, 2000. Disponível em: https://edoc.huberlin.de/bitstream/handle/18452/3093/138.pdf?sequence=1\&isAllowed=y. Acesso em: 02 abr. 2021.

ORGANIZAÇÃO PAN-AMERICANA DA SAÚDE, 2020. Entenda a infodemia e a desinformação na luta contra a covid-19 [em linha]. [Acesso em 29 março 2021]. Disponível em: https://iris.paho.org/handle/10665.2/52054

PARISER. Eli, 2011. O filtro invisível: O que a internet está escondendo de você. Tradução de Diego Alfaro. Rio de Janeiro: Zahar.

PINHEIRO, Lena Vânia R, 1999. Campo interdisciplinar da ciência da informação: fronteiras remotas e recentes. Em: PINHEIRO, L.V.R. (Org.) Ciência da informação, ciências sociais e interdisciplinaridade, Brasília: IBICT. 1999. p.155-182.

RUSA, 2008. Diretrizes para a introdução de recursos de informação eletrônica para usuários, American Library Association - ALA [Em linha]. 29 de setembro de 2008. [Acesso em 27 março 2021]. Disponível em: http://www.ala.org/rusa/resources/guidelines/guidelinesintroduction

SANTAELLA, Lucia, 2018. A Pós verdade é verdadeira ou falsa? Organizado por Fabio Cypriano. Barueri, SP: Estação das Letras e Cores.

SANTAELLA, Lucia, 2003. Da cultura das mídias à cibercultura: o advento do póshumano. Revista Famecos [em linha]. 2003. no. 22, p. 23-32. [Acesso em 20 fevereiro 2021]. Disponível em:

https://revistaseletronicas.pucrs.br/ojs/index.php/revistafamecos/article/view/3229/24 93

SARACEVIC, Tefko, 2014. Information Literacy in the United States: Contemporary Transformations and Controversies. Em: Aprendizagem ao longo da vida e cidadania digital no século XXI [em linha]. 2014. vol. 492, p. 19-30. [Acesso em 27 março 2021]. Disponível em:

https://www.researchgate.net/publication/308012310_Information_Literacy_in_the_ United_States_Contemporary_Transformations_and_Controversies

SARACEVIC, Tefko, 1999. Information science. Em: Journal of the American Society for Information Science, Washington. 1999. vol.50, n. 12, p. 1051-1063. 
SILVA, Terezinha Elisabeth da, 1991. Ação cultural e biblioteca pública: algumas questões. Em: Congresso Brasileiro de Biblioteconomia e documentação [Em linha]. Salvador: Associação Profissional dos Bibliotecários do Estado da Bahia.1991. p.6064. [Acesso em 26 março 2021]. Disponível em:

http://eprints.rclis.org/14827/1/AcaoCultural_e_BibliotecaPub.pdf

TOMAÉL, Maria I. et al. Critérios de qualidade para avaliar fontes de informação na internet. In: TOMAÉL, Maria I.; VALENTIM, Marta Lígia Pomim (Org.). Avaliação de fontes de informação na Internet. Londrina: Eduel, 2004. p. 19-40. Disponível em: http://200.18.252.196:8080/pergamumweb/vinculos/000001/000001b3.pdf. Acesso em: 13 mar. 2021.

TOMAÉL, Maria Inês. Fontes de informação na Internet. Londrina: EDUEL, 2008.

VERGUEIRO, Waldomiro. Seleção de materiais de informação: princípios e técnicas. Brasília, Briquete de Lemos. 2010.

UNESCO, 2020. Periodismo, "noticias falsas" e desinformación: manual de educación y capacitación en periodismo [Em linha]. Paris: UNESCO. [Acesso em 27 março 2021]. Disponível em: https://unesdoc.unesco.org/ark:/48223/pfooo0373349.locale=es

WARDLE, Clair, Derakhshan, Hossein, 2017. Information disorder: Toward an interdisciplinary framework for research and policy making [em linha]. France: Council of Europe. [Acesso em 27 março 2021]. Disponível em: https://rm.coe.int/information-disorder-report-november-2017/1680764666 